\title{
WATER CURTAINS FOR FIRE PROTECTION: EXPERIMENTAL TESTS AND CFD MODELLING
}

\author{
FABIO ALAIMO PONZIANI ${ }^{1,2}$, ALBERTO TINABURRI $^{1,2} \&$ VALTER RICCI $^{1}$ \\ ${ }^{1}$ Central Direction for Prevention and Technical Safety Ministry of the Interior; \\ ${ }^{2}$ University of Rome Tor Vergata, Italy
}

\begin{abstract}
The aim of this study is to illustrate some features of the water curtains generated by edge nozzles in order to offer a fire protection mechanism based on water screens. Water curtains from edge nozzles in an experimental setup are firstly investigated in terms of essential characteristics such as hydraulic patterns and heat absorption and then used as a basis for a CFD model. The setup is made with the water curtains used as a screen between a heptane pool as the fire source and an iron plate as the heat target. Several measures of temperature are taken by means of a set of thermocouples placed on the target, both in presence and in absence of the water curtains, to capture the effect of the heat reduction on the target due to the water discharge. The data collected may serve as a basis for some quantifying analysis and for comparisons with different configurations. Further research will involve thermal and hydraulic measures both necessary for preparing CFD models that may be used as a basis for applications in fire safety engineering and useful for assessment in active fire protection design.
\end{abstract}

Keywords: water curtain, edge nozzle, FSE.

\section{EXPERIMENTAL SETUP}

The use of water curtains for fire protection is rapidly developing for its effect of thermal screen under certain conditions, where the microscopic (droplet size and distribution) and macroscopic (angle of width and thickness of the screen) properties can be usefully combined as a mitigating effect on the target of a fire source [1], [2]. Many interactions between a water curtain and a fire source can be activated or not, in some combination among them all, such as cooling effect of the gas phase in combustion, reduction of the oxygen quantity available to feed the fire, dilution of the concentration of flammables vapours, cooling of the liquid film of the combustible surface, cooling of the surface exposed to the fire source, kinetic effects on the chemistry of combustion reaction, attenuation of the radiation absorbed from the fire source. While a typical fire engineering design might use the water curtains to cool a target surface from a fire source, either by directly wetting the surface or by making a radiation screen in between - both of which need to be properly investigated by experimental tests and advanced numerical modelling of the design under consideration - it should not use the water curtains to simply replace a solid boundary necessary for compartmentalization, such as a wall or a side boundary, since the required parameters of fire resistance cannot be guaranteed by a water flow. This study deals with the possible effect of thermal screen by a water curtain placed between a fire source and a receiving target, starting with an experimental setup and developing a CFD modelling.

The experimental setup is designed to assess the hydraulic of the water curtain nozzles and the energy exchange between a flame and a receiving target, both in the absence and in the presence of a water curtain between the fire source and the target. The campaign of tests was carried out in the Laboratories of the Central Direction for Prevention and Technical Safety of the Italian National Firefighters. In the hydraulic tests, the nominal flow rate obtained for the nozzle, that is an edge nozzle having an exit slot of $4 \mathrm{~mm}$ by $20 \mathrm{~mm}$, is 18 $1 / \mathrm{min}$ at a pressure of $6 \mathrm{bar}$, with a water curtain downward issued with an angle of $\sim 120^{\circ}$ in the vertical plane to be used as a thermal screen and of $\sim 6^{\circ}$ in the thickness. Two nozzles are 


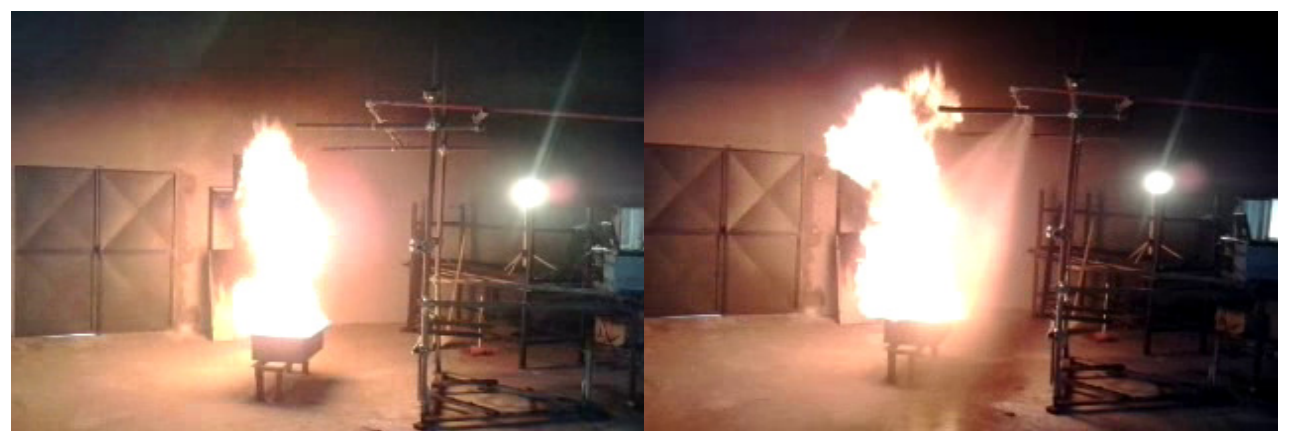

Figure 1: (a) Fire source without water curtains; (b) Fire source with water curtains.

placed side by side, to study the combined effect of two single curtains merging into one in the thermal tests. The two nozzles are placed at a height of $2 \mathrm{~m}$ from the ground, spaced 50 $\mathrm{cm}$ aside from each other, at a distance of $60 \mathrm{~cm}$ from the fire source edge and of $30 \mathrm{~cm}$ from the vertical screen target. The fire source is obtained by the combustion of 10 litres of nheptane poured in a metal pan with water in the bottom to absorb the thermal shock. The pan has a rectangular plan area of about $60 \mathrm{~cm}$ in the long side facing the target and of $40 \mathrm{~cm}$ in the short side with the free surface at a height of $50 \mathrm{~cm}$ from the ground. Once ignited, the flame reaches a height of about $2 \mathrm{~m}$. The target is a screen plate of iron, vertically placed at a distance from the edge of the fire pan of $90 \mathrm{~cm}$, with its bottom edge at a height of $70 \mathrm{~cm}$ from the ground, with a square side of $1 \mathrm{~m}$, hence an area of $1 \mathrm{~m}^{2}$, and a thickness of $10 \mathrm{~mm}$. Behind the target screen, five thermocouples are placed in the centre and in the four corners, to record the temperature histories during the tests on a data logger.

In this work, two experimental thermal tests are considered: the former with the fire source in the absence of the water curtains operating, the latter with the fire source and the water curtains with the two nozzles discharging a downward water flow. In both tests, the fire burned until fuel consumption. In the test with no water curtains operating, the fire burned from the start for about $600 \mathrm{~s}$ and the flames maintained a vertical orientation following their buoyancy and the natural thrust toward the vent in the ceiling above, with the convective air currents interacting between the fire and the environment with no other sign of entrainment as shown in Fig. 1(a). In the test with the water curtains operating, while the fire burned again from the beginning of the experiment, the water was discharged starting from $300 \mathrm{~s}$ to $600 \mathrm{~s}$; the flame envelope was partially influenced by the water stream, due to a deviation from the vertical, resulting in a waving of the flames as shown in Fig. 1(b) and in a shorter duration of the fire of about $400 \mathrm{~s}$.

\section{NUMERICAL MODELLING}

The numerical simulation is performed with the CFD package Fire Dynamics Simulator [3], [4] and Smokeview [5], [6], version 6, modelling a domain bounded on bottom and top and opened to the sides representing the effective part of the space where the interactions from the fire source and the target screen with the water curtains in between are mostly present. The domain is $4 \mathrm{~m}$ wide and deep, $5 \mathrm{~m}$ high, with a bottom floor and a top ceiling with an open vent above the fire source. The common features across the simulations regard the domain volume, the relative position of the interacting elements (fire source - water curtain - target screen), the water curtain angles, the water flow initialization of velocity and droplet distribution, the target screen receiving the heat from the fire. Different fire source models 
and water curtain characterization are considered. Sensitivity analyses have been performed to investigate the effect of the mesh grid and of the droplet size. The domain is subdivided in one single mesh formed by cubic cells of $10 \mathrm{~cm}$ or $5 \mathrm{~cm}$ size (sensitivity on the mesh), with the boundaries modelling the concrete floor and ceiling slabs. The water curtain angles are based on visual observations, issuing from each one of the two edge nozzles a span of $120^{\circ}$ in the vertical plane viewed from the thermal source and of $6^{\circ}$ in the thickness. The velocity of the water issued by each nozzle comes from the nominal data of the nozzle (18.1/min at 6 bar) and the slot opening ( $4 \mathrm{~mm}$ by $20 \mathrm{~mm}$ ), to give a downward velocity of $3.75 \mathrm{~m} / \mathrm{s}$. The statistical size droplet distribution and injection in the domain from each nozzle are left as the default given by the CFD package (Rosin-Rammler-Lognormal, 5000 particles per second injection). The target screen receiving the heat from the fire source is an iron plate, having a surface area of $1 \mathrm{~m}^{2}$ and a thickness of $1 \mathrm{~cm}$, whose thermo-physical characteristics are taken from the literature survey [2]. The setup activates the radiant exchange in the near field and therefore the numerical results are highly sensitive to the modelling of the fire source, of the radiation transport and of its interaction with the water curtains.

The fire source is modelled in three different ways: a burner, a pool, a radiant emitter (Fig. 2). The burner models the combustion of n-heptane giving a quantity of firepower [kW] from a base area of release, the pool models the combustion of n-heptane from a liquid pool of containment, the emitter models the release of radiant energy from a vertical rectangular surface held at constant temperature facing the target. The measures and the observations of the experiments have been used to start or update the models: the horizontal area of the fire pan and the height of the free surface in the pool of $n$-heptane contained are directly used to define the base and the height from the ground of the burner in the first model and are similarly used in the case of the liquid pool with the additional figure regarding the volume of the liquid combustible needed to define the thickness. In the last model, the radiant emitter is a vertical plane having the same width of the pan (i.e. the dimension of the side parallel to the target plate).

The burner model requires as an input the specific firepower $\left(\mathrm{kW} / \mathrm{m}^{2}\right)$. In the absence of experimental data, this figure can be usually derived from empirical correlations requiring the knowledge of the firepower associated with the characteristic fire area (that in our case is the pan base area) [8], [9]. Since liquid pools are characterized by steady state burning conditions, a single constant value of firepower (kW) is needed for the simulation.

The pool model requires for its implementation on FDS only a limited set of thermochemical and physical properties which can be usually found in the literature for ordinary liquid combustibles [2], [3], [7]. This model automatically calculates the combustible

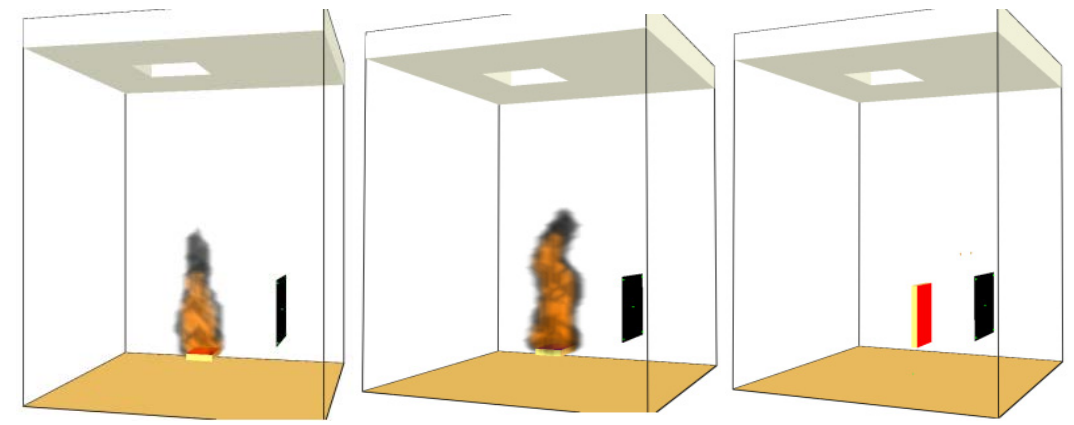

Figure 2: (a) Fire burner; (b) Pool fire; (c) Radiant emitter. 
mass loss rate and the firepower: the radiative fluxes emitted by the flame and the duration of the combustion derive therefore from the model itself and caution must be posed by the designer to check if the results thus obtained are consistent with experimental figures or empirical correlations.

The emitter model is a simplified approach that models the flame as vertical plane, requiring as an input the surface temperature of the plane and its dimensions. In this case, the width is the same of the longer side of the pan and the height is linked to the persistent flame height, which can be usually derived from empirical correlations requiring the knowledge of the firepower combined with the characteristic fire diameter (that in our case is the pan equivalent diameter) [8], [9]; the temperature of the emitter can be assumed constant for liquid pools and it can be derived from the incident flux on the target obtained with the burner model.

While the pool model activates the fire source until fuel consumption, the burner and the emitter models require the time window of fire source activity to be set in advance. This can be done knowing, for instance, the duration of experimental tests or of similar arrangements. The results obtained from the experiments highlighted the necessity to tune the numerical models for the burner and the radiant emitter. Even if the pool fire model implementation is based on input data taken from the literature, caution should be posed in using the calculated radiant flux for design purposes. In our study, the pool fire model resulted in a shorter flame duration $(\sim 380 \mathrm{~s})$ compared to the experimental value $(\sim 600 \mathrm{~s})$ due to the overestimation of the combustible gas flow rate evaporating from the liquid surface. This means that even in this case some parameters in the model should be tuned, for example those available to describe the efficiency of combustion. The knowledge of the duration of the flaming phase is a valuable information to check the numerical model adopted to describe the fire source.

Water curtains characterization requires detailed information of microscopic (droplet size and distribution) and macroscopic (angle of width and thickness of the screen) properties.

Lacking specific measurements, the water curtains droplet size is modelled with three different values selected in the range typical for the operating condition under study. Since the droplet size, that is the median volumetric droplet diameter, statistically describes the water flow pattern, it helps to distinguish between different possible characteristics and behaviours [1], [2]: the finer diameters (on the order of magnitude $100 \mu \mathrm{m}$ ) are those more useful to make thermal screens. On these basis, the values of the median volumetric droplet diameter chosen for the numerical initializations are $100 \mu \mathrm{m}, 200 \mu \mathrm{m}, 400 \mu \mathrm{m}$, with the intermediate value as the baseline (sensitivity on the effect) as shown in Fig. 3.

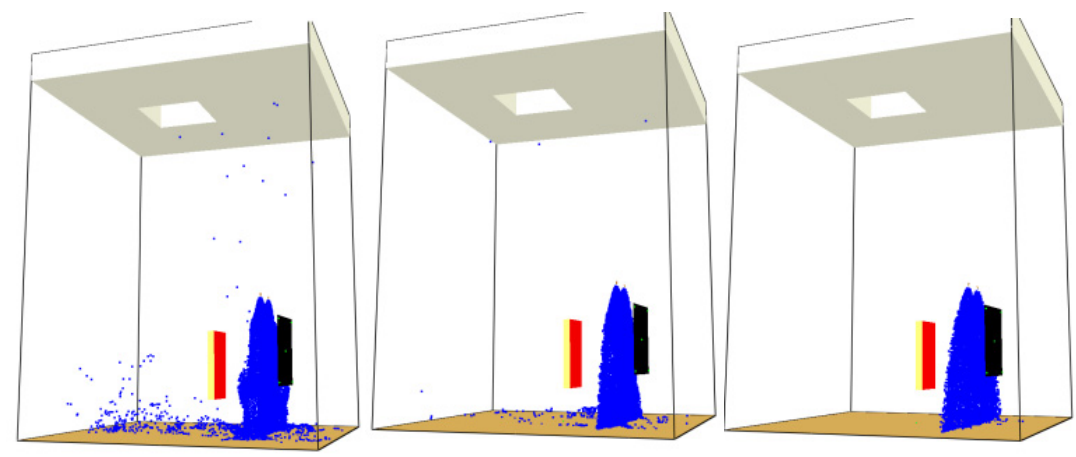

Figure 3: Droplets size (a) $100 \mu \mathrm{m}$; (b) $200 \mu \mathrm{m}$; (c) $400 \mu \mathrm{m}$. 


\section{RESULTS}

The output of each simulation run is:

1. the temperature history on the target, using proper devices positioned on the target screen in the same way the thermocouples were positioned in the experimental setup;

2. the incident heat flux received from the target, using one device present only in the simulations;

3. a numerical control over the total water flowing from the nozzles.

While the devices for the temperature positioned in the corners of the target may be useful to monitoring the trends, the devices at the centre of the target for the temperature and the incident heat flux are better suited for comparisons and deductions with the data obtained from the experiments. This is principally due to the fact that the CFD package treats the heat conduction in the solids in a 1D manner, so the edge effects that are present in the corners of the target plate may not be adequately resolved, unless a process of $2 \mathrm{D}$ heat diffusion compensates reducing the differences between the centre and the corners of the plate during a time compatible with the simulation duration. Furthermore, some effects due to the view factors from the target to the fire source may oscillate from the corners, since the flame fluctuations are not necessarily exactly the same between the real phenomenon in the experiments and the model shape in the simulations.

The results obtained from the simulations without water curtains operating are summarized in Fig. 4 using the temperature rise at the centre of the target facing the fire source. The simulations are grouped depending on the type of fire source model: burner vs pool vs radiant emitter. For the burner model, the constant firepower input is $\sim 500 \mathrm{~kW}$ while for the radiant emitter the constant surface temperature is $700^{\circ} \mathrm{C}$.

Reference cell grid size is $10 \mathrm{~cm}$ for all simulations except for the case of the burner in which the effect of a mesh reduction to $5 \mathrm{~cm}$ is investigated. The simulation runtime is fixed to $600 \mathrm{~s}$ as the observed experimental duration of the flaming phase in the absence of water discharge; in the case of the pool fire this duration does not correspond to the duration of the flaming phase as in this model this event derives from the complete consumption of the liquid combustible volume.

The results obtained from the simulations with water curtains operating are summarized in Fig. 5. Considering the results obtained, only the burner and the radiant emitter are used as fire source. Reference cell grid size is kept constant to $10 \mathrm{~cm}$ and the effect of the water droplet mean diameter (100 vs 200 vs $400 \mu \mathrm{m}$ ) is investigated with the baseline being 200 $\mu \mathrm{m}$. The simulation runtime is fixed to $600 \mathrm{~s}$ and the water discharge starts from $300 \mathrm{~s}$.

Incident heat flux on the centre of the target face exposed to the fire with and without water curtains operating, calculated with the numerical model with the reference cell grid of $10 \mathrm{~cm}$, is reported in Table 1 . In the case of no water discharge, data are the averaged values in the time interval 50-350 s, where the flame presence is always guaranteed. In the case of water curtains operating, data are the averaged values in the time interval $350-500 \mathrm{~s}$, where the flame presence is always guaranteed.

Due to the relative accuracy of the result obtained in the absence of the water curtains and taking into account the computational effort required, the sensitivity analysis on droplet size has been performed using the radiant emitter fire source model. As expected, the pool fire gives the highest incident flux on the target, as a consequence of the calculated evaporation rate from the liquid surface. Hence, it has been skipped from further analysis with the water curtains operating. 

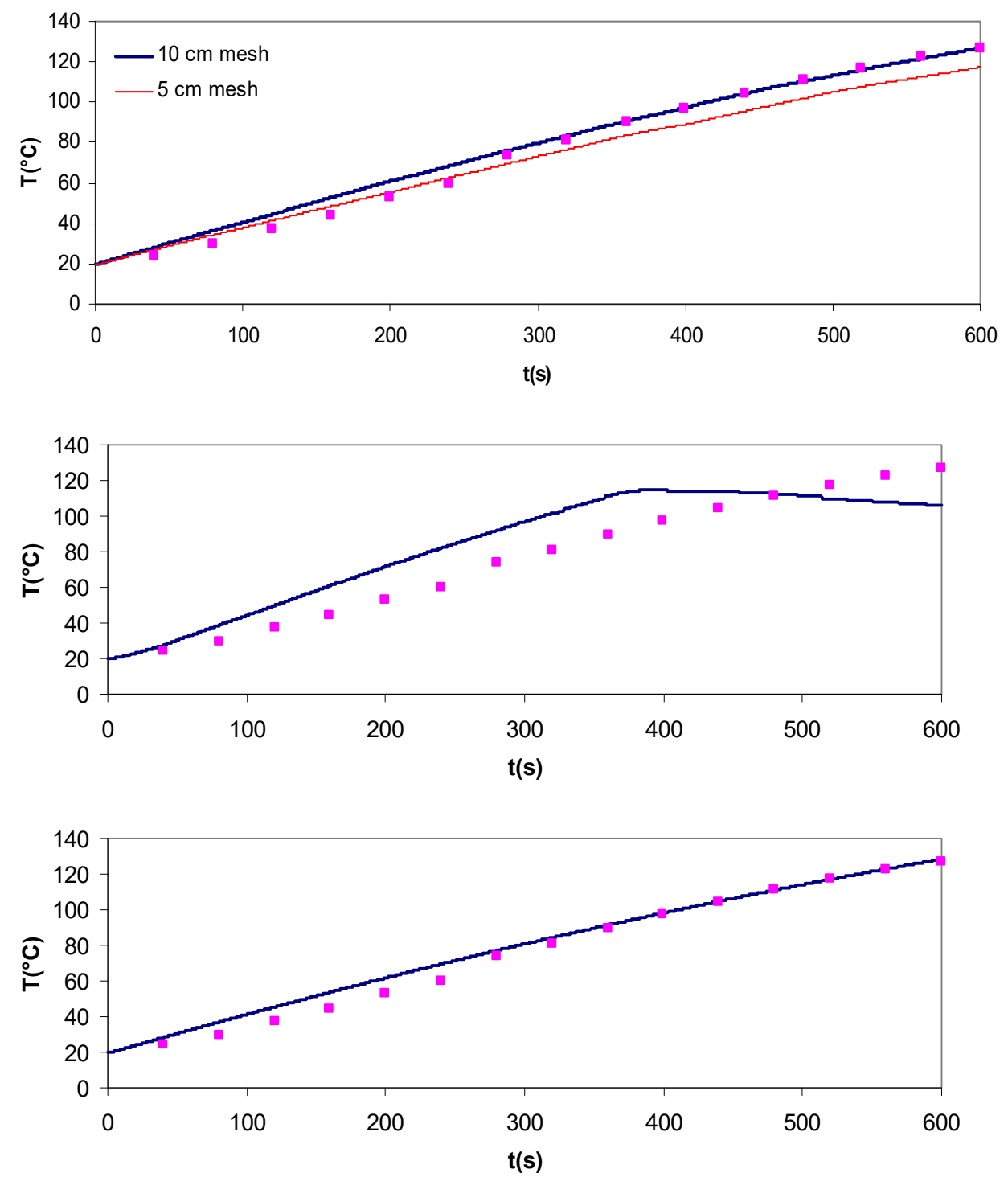

Figure 4: No water curtains with fire source. (a) Burner; (b) Pool; (c) Radiant emitter. 

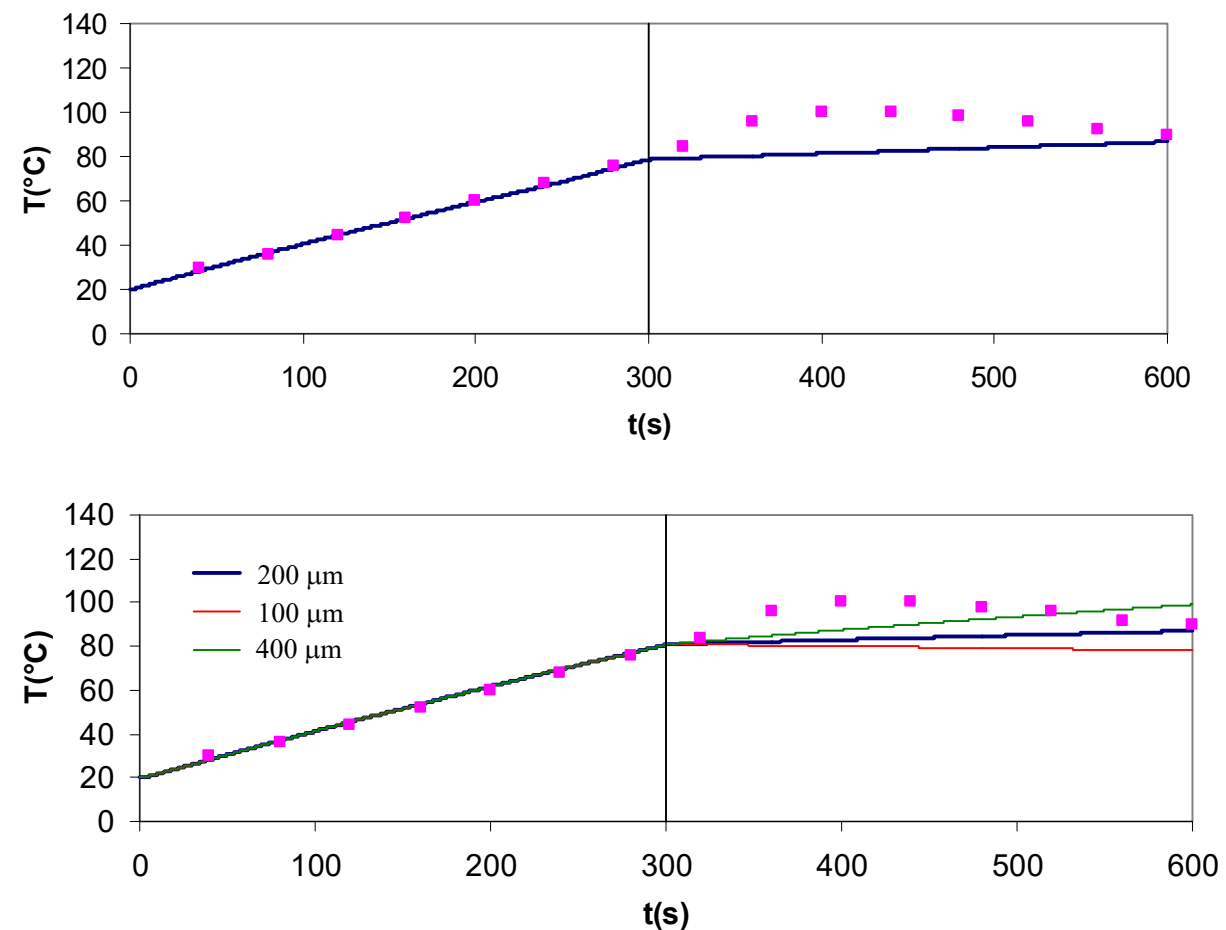

Figure 5: Water curtains with fire source. (a) Burner; (b) Radiant emitter.

Table 1: Incident heat flux on the centre of the target, calculated with $10 \mathrm{~cm}$ cubic cells.

\begin{tabular}{|c|c|c|}
\hline $\begin{array}{c}\text { Fire source } \\
\text { model }\end{array}$ & $\begin{array}{c}\text { Without } \\
\text { water curtains }\end{array}$ & With water curtains \\
\hline Burner & $8.96 \pm 1.07 \mathrm{~kW} / \mathrm{m}^{2}$ & $2.82 \pm 0.51 \mathrm{~kW} / \mathrm{m}^{2} @ 200 \mu \mathrm{m}$ \\
\hline Radiant & $9.06 \pm 0.09 \mathrm{~kW} / \mathrm{m}^{2}$ & $\begin{array}{c}1.29 \pm 0.02 \mathrm{~kW} / \mathrm{m}^{2} @ 100 \mu \mathrm{m} \\
2.59 \pm 0.02 \mathrm{~kW} / \mathrm{m}^{2} @ 200 \mu \mathrm{m} \\
\text { emitter }\end{array}$ \\
\hline Pool & $11.87 \pm 1.17 \mathrm{~kW} / \mathrm{m}^{2}$ & --- \\
\hline
\end{tabular}

Based on these findings, two reduced domains have been modelled with $1.5 \mathrm{~cm}$ cubic cells to analyse the grid sensitivity. These domains are bounded on bottom only (Fig. 6) and their overall dimensions are $1.95 \mathrm{~m}$ wide, $3 \mathrm{~m}$ deep and high for the fire burner source and $1.5 \mathrm{~m}$ wide, $3 \mathrm{~m}$ deep, $2.1 \mathrm{~m}$ high for the radiant emitter source. The differences take into account the requirements for initializing the pressure field and giving enough room for the entrainment flow to develop in the modelling of the fire burner source. The reduction in the mesh grid size is of one order of magnitude. 

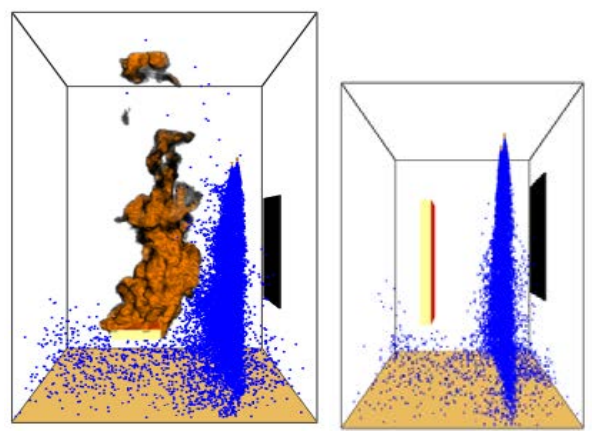

Figure 6: Reduced domains. (a) Fire burner; (b) Radiant emitter.

Table 2: Incident heat flux on the centre of the target, calculated with $1.5 \mathrm{~cm}$ cubic cells.

\begin{tabular}{|c|c|c|}
\hline $\begin{array}{c}\text { Fire source } \\
\text { model }\end{array}$ & $\begin{array}{c}\text { Before operating } \\
\text { water curtains }\end{array}$ & $\begin{array}{c}\text { After operating } \\
\text { water curtains }\end{array}$ \\
\hline Burner & $7.91 \pm 1.88 \mathrm{~kW} / \mathrm{m}^{2}$ & $6.60 \pm 1.76 \mathrm{~kW} / \mathrm{m}^{2} @ 200 \mu \mathrm{m}$ \\
\hline Radiant & $9.59 \pm 0.04 \mathrm{~kW} / \mathrm{m}^{2}$ & $6.35 \pm 0.27 \mathrm{~kW} / \mathrm{m}^{2} @ 200 \mu \mathrm{m}$ \\
emitter & $9.59 \pm 0.04 \mathrm{~kW} / \mathrm{m}^{2}$ & $7.57 \pm 0.15 \mathrm{~kW} / \mathrm{m}^{2} @ 400 \mu \mathrm{m}$ \\
\hline
\end{tabular}

Incident heat flux on the centre of the target face before and after water curtains operating, calculated with the reference cell grid of $1.5 \mathrm{~cm}$ in the reduced domains and shorter run time of $10 \mathrm{~s}$ with water discharge starting after $5 \mathrm{~s}$, to get a preliminary assessment of the radiant flux reduction, is reported in Table 2. Before water discharge, data are the averaged values in the time interval $\sim 3-5 \mathrm{~s}$; after water curtains operating, data are the averaged values in the time interval $\sim 6-9 \mathrm{~s}$.

This refinement gives insight on some results obtained for the incident heat flux on the centre of the target facing the thermal source. It should be noted that some numerical instability appears when the combustion is activated and the mesh grid cell is in this order of magnitude $(\sim 1 \mathrm{~cm})$.

\section{CONCLUSION}

Work on this research area is in progress especially for the modelling of the near field.

From the simulation results reported in tables 1 and 2, the assessment of the incident heat flux reduction in the near field due to water curtains is highly sensitive to the model assumptions (mainly mesh grid and droplet size), with calculated results ranging from $17 \%$ to $85 \%$. For this specific application, numerical modelling alone is not sufficient to obtain accurate results for design purposes: only a combined use of information acquired through numerical simulation and physical tests makes it possible to assess and compare different design strategies.

Further studies are required to improve the modelling of the fire source and the characterization of the water curtains. An experimental campaign is scheduled to directly obtain the measurements of the incident heat flux on the target, the droplet size distribution, the initial velocity and spray angles from the edge nozzle.

To summarize, the aim of this study was to illustrate how CFD may be an advantageous tool to help manage fire-fighting matters, especially when matched with experimental 
observations. For the water curtains, several results have been obtained by combining physical and numerical information in order to compare the influence of fire source and of the water droplets models.

\section{REFERENCES}

[1] Roytman, M.Y., Principles of fire safety standards for building construction, Amerind, USA, 1975.

[2] Di Nenno, P.J., The SFPE Handbook of Fire Protection Engineering, NFPA, 2015.

[3] Fire Dynamics Simulator (Version 6) - Technical Reference Guide; NIST Special Publication 1018, 2014, Online. http://www.nist.gov/el/fire_research/ fds_smokeview.cfm.

[4] Fire Dynamics Simulator (Version 6) - User's Guide; NIST Special Publication 1019, 2014, Online. http://www.nist.gov/el/fire_research/fds_smokeview.cfm.

[5] Smokeview (Version 6) - Technical Reference Guide, NIST Special Publication 10172, 2014, Online. http://www.nist.gov/el/fire_research/fds_smokeview.cfm.

[6] Smokeview (Version 6) - User's Guide, NIST Special Publication 1017-1, 2014, Online. http://www.nist.gov/el/fire_research/fds_smokeview.cfm.

[7] Fire Dynamics Simulator (Version 6) - Validation Guide; NIST Special Publication 1018, 2014, Online. http://www.nist.gov/el/fire_research/fds_smokeview.cfm.

[8] Karlsson, B. \& Quintiere, J.G., Enclosure Fire Dynamics, CRC Press, New York, USA, 2000.

[9] Quintiere, J.G., Fundamentals of Fire Phenomena, John Wiley \& Sons, New York, USA, 2006. 